\title{
Severe autogenously fecal peritonitis in ageing Wistar rats. Response to intravenous meropenem ${ }^{1}$
}

\author{
Guilherme Veras Mascena', Maria Cecília Santos Cavalcanti Melo" ${ }^{\text {II }}$ Diego Nery Benevides Gadelha ${ }^{\text {III }}$ Thárcia Kiara \\ Beserra Oliveira $^{\mathrm{IV}}$, Carlos Teixeira Brandt ${ }^{\mathrm{V}}$
}

DOI: http://dx.doi.org/10.1590/S0102-8650201400150010

IFellow MSc degree, Postgraduate Program in Surgery, Health Sciences Center, Federal University of Pernambuco (UFPE). Assistant Professor, Department of Ophthalmology, Campina Grande Faculty of Medicine (FCM), Campina Grande-PB, Brazil. Acquisition and interpretation of data, manuscript writing.

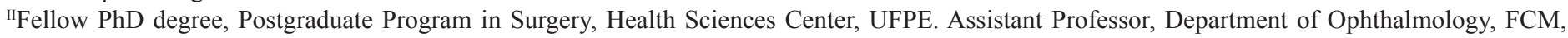
Campina Grande-PB, Brazil. Acquisition and interpretation of data.

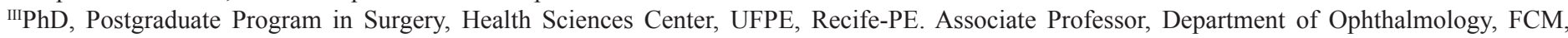
Campina Grande-PB, Brazil. Manuscript writing, critical revision.

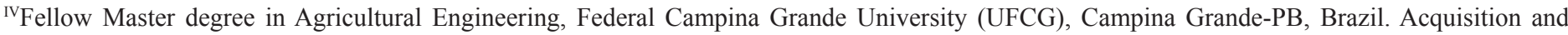
interpretation of data.

${ }^{\mathrm{v}} \mathrm{PhD}$, Head Professor, Scientific Methodology and Pediatric Surgery, UFPE, Recife-PE. Scientific director, FCM, Campina Grande-PB, Brazil. Interpretation of data, English version, final revision.

\begin{abstract}
PURPOSE: To evaluate the treatment outcome of severe peritonitis in rats with increasing age.

METHODS: Thirty Wistar rats stratified in three groups: group I - six month-old; group II - 12 month-old; and group III - 18 monthold, underwent autogenously fecal peritonitis $(6 \mathrm{ml} / \mathrm{kg} \mathrm{rat})$, and were treated with intravenous meropenem. The survival animals were followed-up for 45 days. The variables were expressed by their mean and standard error of the mean (SEM). $p<0.05$ was used for rejecting the null hypothesis. The study was approved by the Ethics Committee.

RESULTS: There was a significant increase in the mortality and morbidity in elderly rats. Of interest, even among young survival rats presenting with severe residual abscesses both in the abdomen and thorax cavities, they present an almost normal life.

CONCLUSIONS: The treatment of severe autogenously fecal peritonitis with intravenous meropenem reached reasonable results in rats with six and twelve months of age, even considering residual abscesses on abdomen and thorax cavities. However, the great majority (80\%) of elderly rats could not overcome the initial severe infectious challenge, proving that ageing is a very important risk factor for impairing immune response. Thus, sepsis remains a challenging situation, especially in elderly.
\end{abstract}

Key words: Peritonitis. Carbapenems. Therapy. Rats. 


\section{Introduction}

Advanced age, in human beings, has long been identified as a major risk factor for the development of postoperative septic complications following abdominal surgery ${ }^{1}$. It is now becoming evident that the immune system undergoes ageassociated alterations, which accumulate to produce a progressive deterioration in the ability to respond to infections that is associated with a higher mortality rate in the elderly ${ }^{2}$. Thus, ageing is a complex phenomenon that negatively impacts the development of the immune system and its ability to function ${ }^{3}$.

Since 1987, there has been evidence that age-related difference in the pathophysiology of intraabdominal sepsis in rats. A more efficient bacterial clearance and a higher phagocytic activity in the peritoneal macrophages of the suckling rats could be one of aspect of the better immune response in these young animals ${ }^{4}$.

Several interventional approaches for treating intraabdominal sepsis in rat model describe the animals as adult male, Wistar-albino rats weighing from 250 to 320 g. However, chronological ages are not specified in most of the studies ${ }^{5-7}$. On the other hand, some studies used very young Wistar rats (age between two and three months, and weight between 200 and $250 \mathrm{~g})^{8}$.

The increased sensitivity of aged mice to invasive bacterial infection documented in one paper, according well with human epidemiological experience, demonstrated the appropriateness of the model for continued investigations of sepsis in the aged 9 .

Since 2009, carbapenems have been used in patients with secondary widespread peritonitis ${ }^{10,11}$, from 2010 meropenembased schemes allowed for significantly higher rates of appropriate/adequate therapy in critically ill patients especially those with severe nosocomial infections, infected with multidrugresistant microrganisms ${ }^{12}$. Meropenem tends to provide better antibiotic coverage for spontaneous bacterial peritonitis in severe patients with cirrhosis when compared with third generation cephalosporin $^{13}$, and for other sepsis due to secondary peritonitis ${ }^{14}$.

Although there has been several reports dealing with the increasing resistance to meropenem, in the last two years, from microorganisms that grow in intensive care units and hospital facilities, this antimicrobial substance still is one of the best empirical drug for first option for severe critically infected ill patients without knowing the bacteriological tests ${ }^{15}$.

The purpose of this investigation was twofold: 1 to investigate the impact of increasing age of a rat model for autogenously fecal peritonitis; and 2 - to analyze the effect of intravenously meropenem in rats from different ages that have undergone to severe peritonitis.

\section{Methods}

The research was approved by the Institutional Research Ethics Committee of Animal Experimentation of FCM, Campina Grande-PB. This was a prospective, analytical and experimental study.

Adult Wistar rats (Rattus norvegicus, rodentia mammalia) from the animal house were used for this study. They were housed in polypropylene cages, four animals per cage, under standard light/dark conditions (lights on 7:00, off 19:00) with food pellets and water ad libitum. One rat had to be excluded because it presented with a tooth malformation and developed malnutrition. It was replaced by other animal from the same litter.

Peritonitis was induced, in 30 inbred rats stratified in three groups of 10, - group I with chronological age of six months; group II with chronological age of 12 months, and group III with chronological age of 18 months, by intra-peritoneal inoculation of a $10 \%$ suspension of autogenously feces. Two grams of stools were collected for each own individually rat and dissolved in 20 $\mathrm{ml}$ of $0.9 \%$ saline solution. This mixture was homogenized and filtered through gauze in order to remove large particles. It was injected $6 \mathrm{ml} / \mathrm{kg}$ of the suspension in the intra-peritoneal cavity, in the left iliac quadrant, using a $30 \times 12 \mathrm{~mm}$ needle. The rats had to have regular bowel habits and no macroscopic feces changes (blood, mucus or pus).

After eight days following induction of autogenously fecal peritonitis it was injected intravenously (iv) meropenem at a single dosage of $40 \mathrm{mg} / \mathrm{kg}$. This protocol was done in groups I and II. However, in group III, it was changed because of the high mortality of these old animals in the first two days following peritonitis induction. The six animals that survived after $24 \mathrm{~h}$ received IV meropenem $(40 \mathrm{mg} / \mathrm{kg}$ ) daily. Two old rats that were still alive in the third day after autogenously fecal peritonitis received another intravenous shot of meropenem.

The animals were observed, by the veterinary, as regard to: activity, body weight and temperature, respiratory rate and hair status, with the goal of obtaining signs of serious infection.

The animals that died before and after antibiotics treatment and those that survived for 45 days after fecal peritonitis induction were euthanized for abdominal and thorax inspection for: abscess identification, adhesions and macroscopic infection signs like pus inside or in the solid organs. Photos were taken for documentation.

To stratify morbidity and mortality it was used a modified protocol validated previously ${ }^{16}$.

Score 0 - Animals that died of septic shock in the first 24 hours after induction of fecal peritonitis; 
Score 1 - Animals that died from septic shock between 24 and 48 hours after induction of peritonitis;

Score 2 - Animals that died between 48 hours and eight days after the induction of peritonitis, with obvious clinical signs of serious infection;

Score 3 - Animals that died between eight and 45 days after the induction of peritonitis, with obvious clinical signs of serious infection;

Score 4 - Animals that survived until 45th day, but still have positive blood culture, with moderate clinical signs of infection and after the euthanasia have abscesses inside the abdomen and thorax cavities.

Score 5 - Animals that survived until 45th day after the induction of fecal peritonitis and still have positive blood culture, with no clinical signs of infection, but after the euthanasia, abscesses inside the abdomen and thorax cavities were observed;

Score 6 - Animals that survived until 45th day after the induction of fecal peritonitis and still have positive blood culture, no clinical signs of infection and after the euthanasia, abscesses only inside the abdomen cavity were observed;

Score 7 - Animals that survived until 45th day after the induction of fecal peritonitis but has negative blood culture, no clinical signs of infection and after the euthanasia, abscesses inside the abdomen and thorax cavities were observed;

Score 8 - Animals that survived until 45 th day after the induction of fecal peritonitis, have negative blood culture and after the euthanasia, however abscesses were only observed inside the abdomen cavity;

Score 9 - Animals that survived until 45th day after the induction of fecal peritonitis, have negative blood culture and after the euthanasia, and only one small abscess was observed inside the abdomen cavity;

Score 10 - Animals that survived until 45th day after the induction of fecal peritonitis, have negative blood culture and after the euthanasia, abscesses inside the abdomen and thorax cavities were not observed.

The scores were expressed by their mean and standard error of the mean (SEM) and the qualitative by their frequencies. For assessing the mean difference it was used Mann Whitney test. The significance level was $95 \%(\mathrm{p} \leq 0.05)$.

\section{Results}

The mortality in groups I and II was no different. One (10\%) rat from each group died before eight days after the severe autogenously fecal peritonitis. The survival animals from both groups were apparently healthy and gaining weight after 45 days post peritonitis induction and had received an intravenous single dosage of meropenem in the $8^{\text {th }}$ day of this event. The residual findings of peritonitis on the inventory of the abdominal and thorax cavities although tended to be more impressive (residual signs of severe infection) on rats from group II (twelve-month old), however the mean scores difference of morbidity and mortality did not reach statistical significance $\{$ (Group I - $7.400 \pm 0.968$ versus Group II - $7.700 \pm$ 0.803 ) - Mann Whitney $U$ test $=47.50-p=0.8657\}$. Figures 1 to 7.

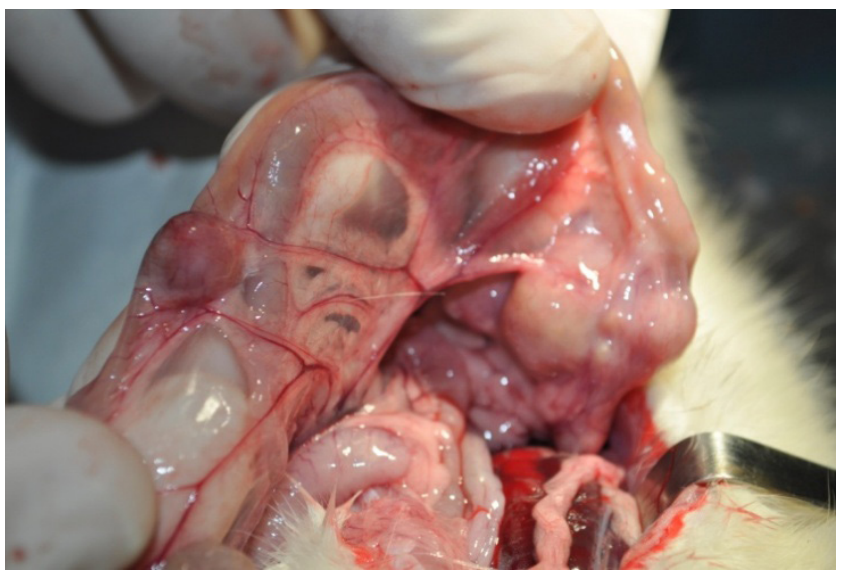

FIGURE 1 - Several large residual abscesses in the small gut mesentery (group I). Rat living normal life.

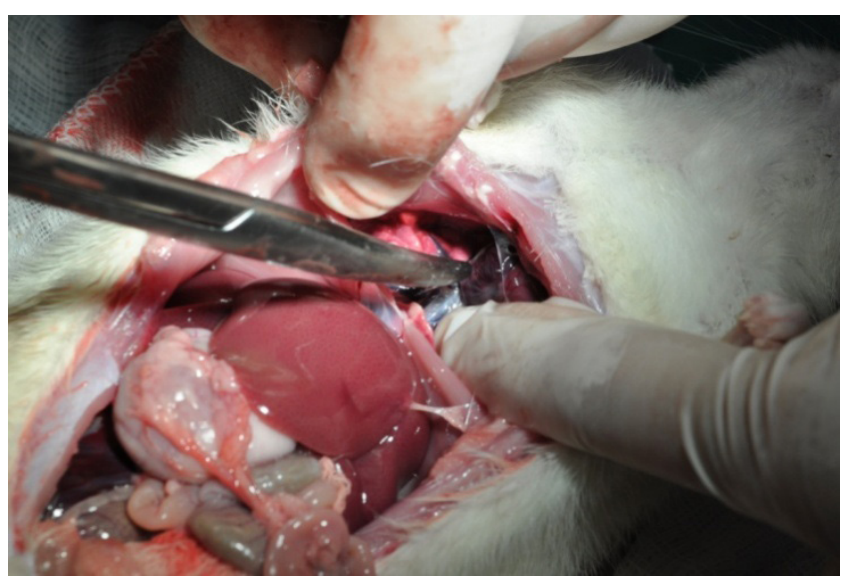

FIGURE 2 - Orange petechiae in the liver (group I). Rat living normal life.

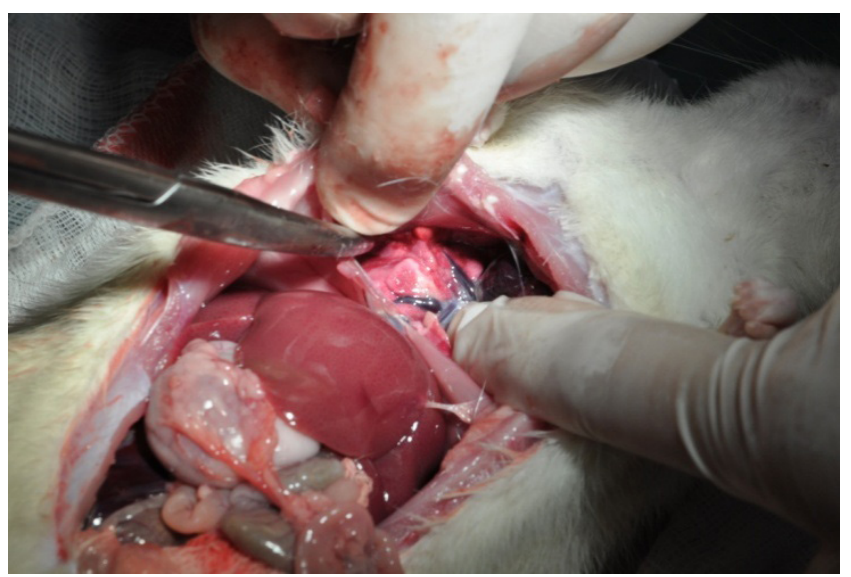

FIGURE 3 - Orange petechiae in the liver (group I) and scar and residual abscesses in the right lung. Rat living normal life. 


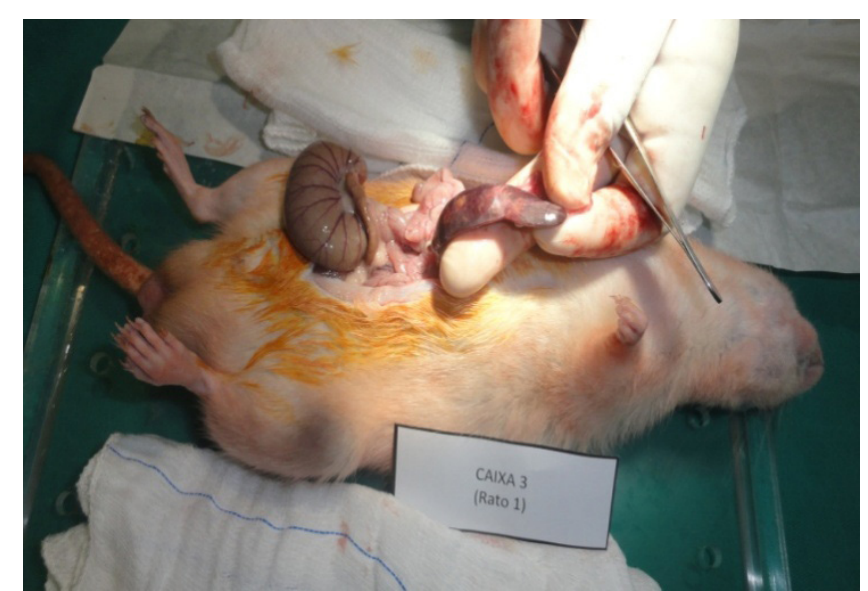

FIGURE 4 - Multiple residual abscesses in the spleen (group II). Rat living normal life.

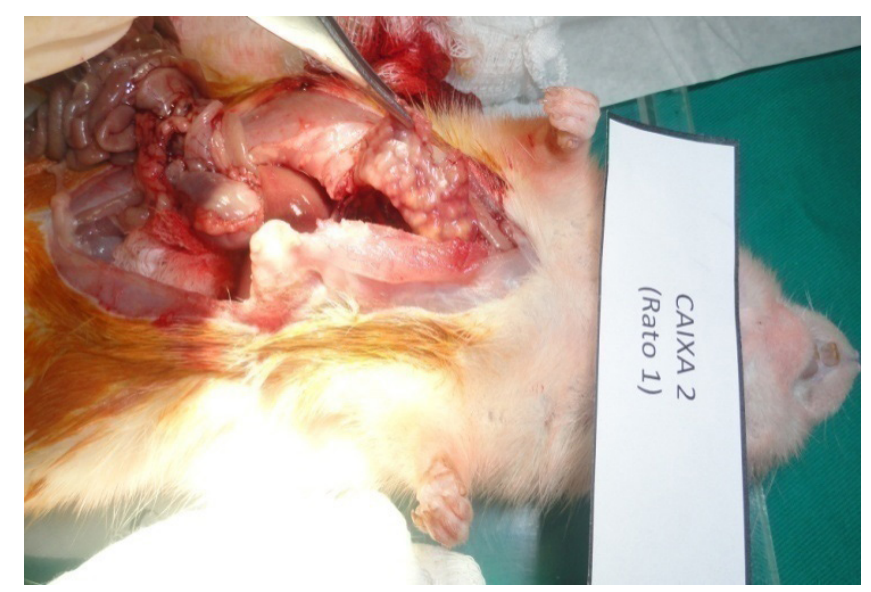

FIGURE 5 - Multiple left lung abscesses (group II). Rat living normal life.

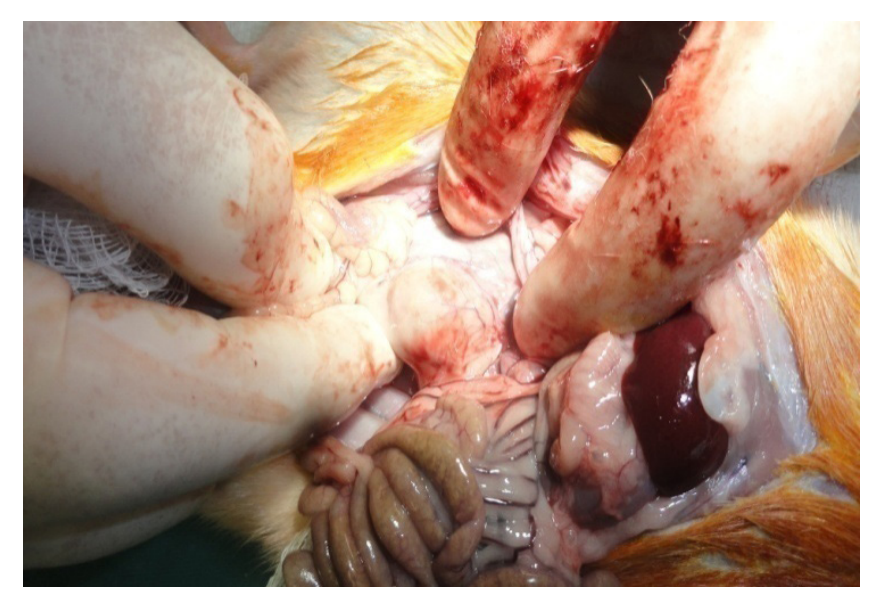

FIGURE 6 - Diffuse residual abscesses in the right kidney, changing the natural color of this organ (group II). Rat living normal life.

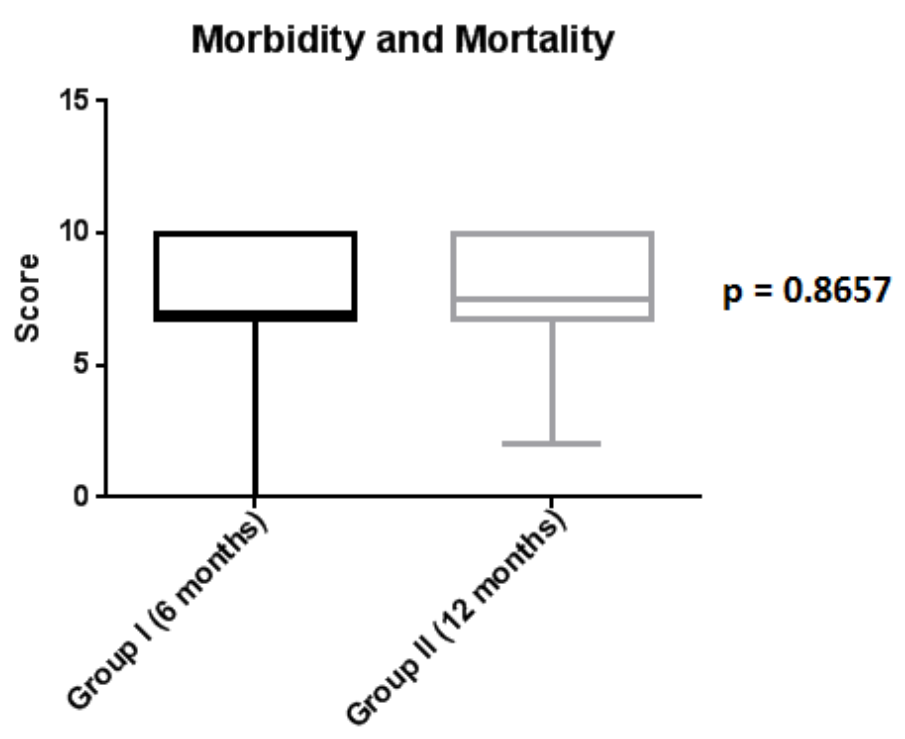

FIGURE 7 - Box plot expressing no significant difference between the measures of central tendency for scores of both groups.

The more frequent gross findings in the abdomen and the thorax cavities in the necropsy analysis in the survival rats from both groups were: a) Adhesion from the small gut to the parietal peritoneum; b) Multiple abscesses in the lungs; b) Residual scar from abscesses in the lungs; c) Orange petechiae in the liver; d) Retroperitoneal abscesses; e) Orange petechiae in the kidney; f) Infrarenal abscesses; g) Residual kidney abscesses; h) Single or multiple mesenteric abscesses; and i) Splenic abscesses.

In group III (elderly group composite of obese and sedentary animals), four (40\%) rats died after 24 hours of peritonitis induction. Two (20\%) animals died about 28 hours after peritonitis induction, but they already have received an intravenously shot of meropenem $(40 \mathrm{mg} / \mathrm{kg})$, four hours before death. One animal (10\%) died at 36 hours of peritonitis induction and 12 hours following meropenem injection. One (10\%) more rat died 24 hours after meropenem shot $(48 \mathrm{~h}$ after peritonitis induction). The two (20\%) survival rats received three shots of intravenously meropenem at the same dosage, $24 \mathrm{~h}, 48 \mathrm{~h}$, and $72 \mathrm{~h}$ after peritonitis induction and they lived for the 45 days according to protocol when they were euthanized for inventory of abdomen and thorax cavities.

Necropsy studies on the eight elderly rats that died in the first 48 hours after peritonitis induction revealed a turbid liquid into the abdominal cavity and collapsed hemorrhagic lungs with orange patches on the surface (Figures 8 and 9). 


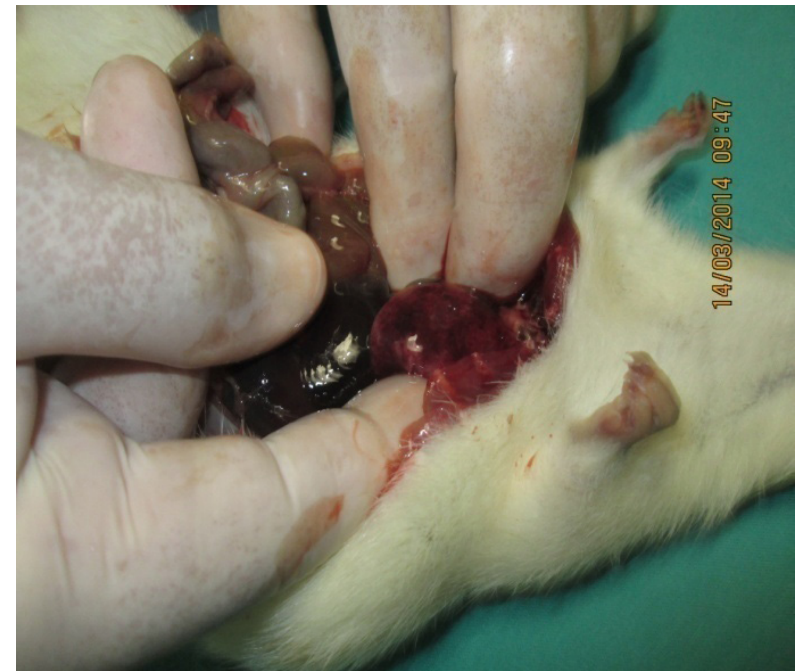

FIGURE 8 - Left lung surface showing hemorrhagic and orange patch areas.

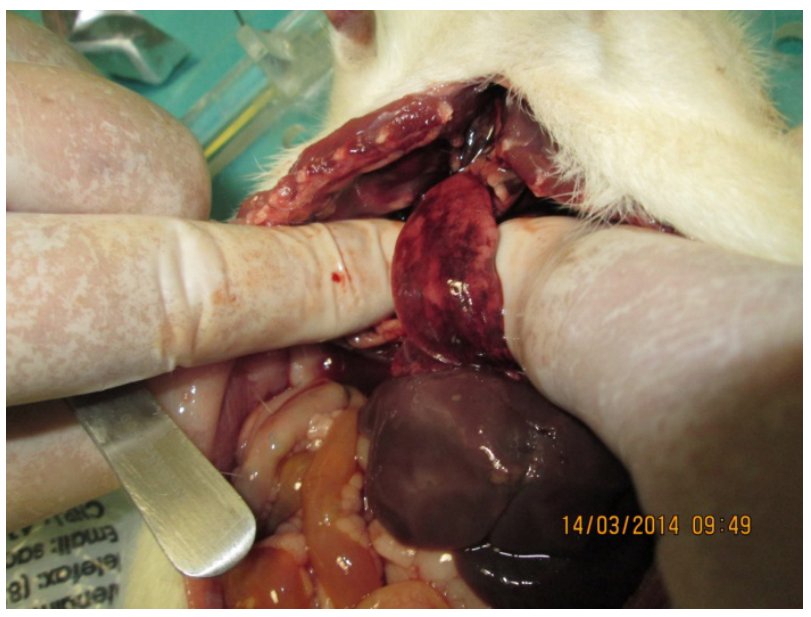

FIGURE 9 - Closer view of the right lung surface showing diffuse hemorrhagic organ and orange patch areas.

The inventory of the abdomen and thorax cavities, after 45 days survival, showed: in one rat a large $(4 \mathrm{~cm} \times 3 \mathrm{~cm})$ resolving abscess located in the posterior retroperitoneal area just in the left inferior quadrant of the abdomen and resolving abscess lesions on the surface of both lungs; in the other it was observed two small abscesses in the mesentery binding different small bowel segments and also resolving abscess lesions on the surface of both lungs. Both animals were gaining weight and were presenting normal behavior (Figures 10 and 11).
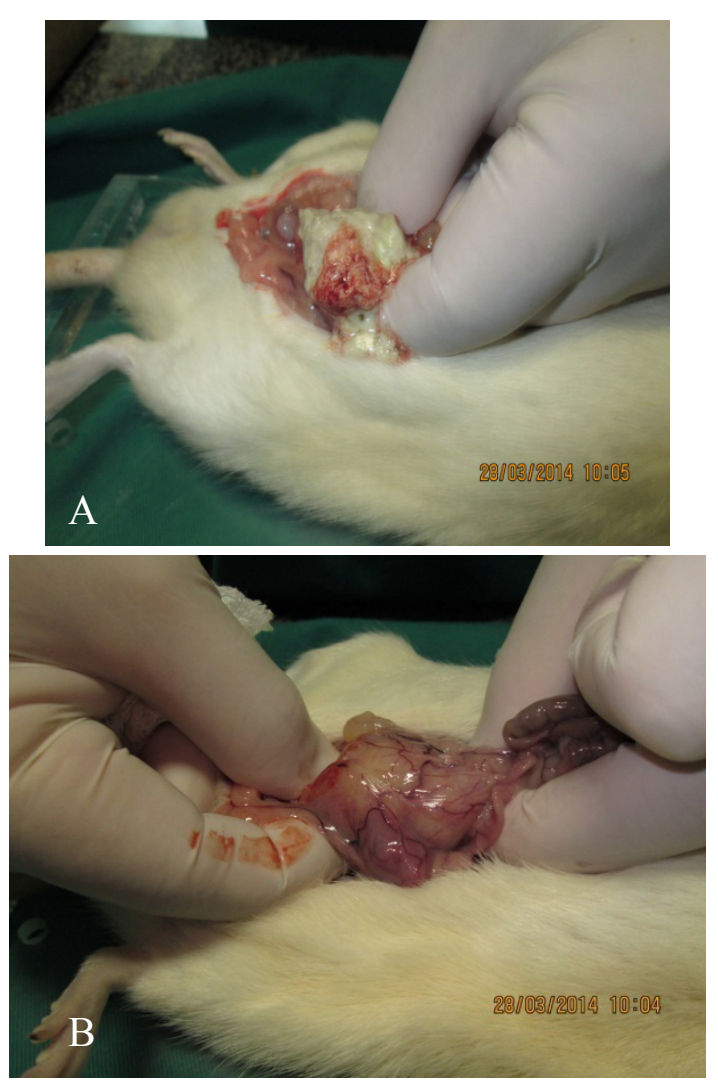

FIGURE 10 - A. Large retro-peritoneal abscess in the left lower abdominal quadrant was observed. B. After opening the abscess there was drainage of necrotic purulent mass.

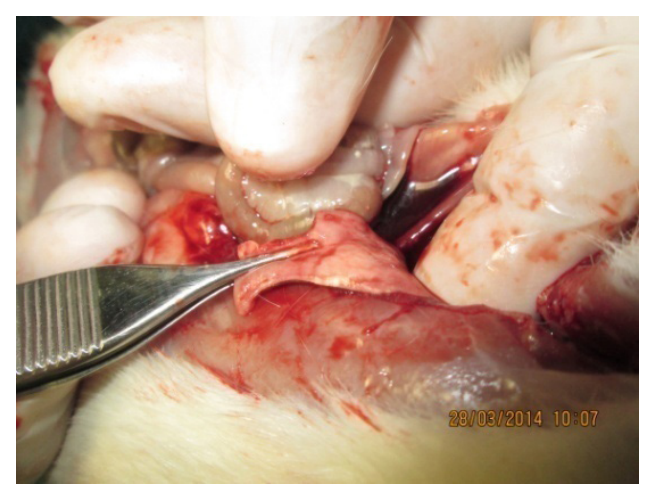

FIGURE 11 - Several abscesses was observed in the surface of lung.

\section{Discussion}

Populations encompassing elderly, have greater mortality from sepsis. The increased mortality observed in this population after sepsis is due to fundamental differences in host-protective immunity and is manifested at the level of the leukocyte transcriptome. In mice, elderly exhibited significantly greater mortality to sepsis. Elderly mice are more susceptible to abdominal peritonitis associated with no significant differences in the magnitude of the inflammatory response, reduced bacterial 
killing, reduced early myeloid cell activation, and a persistent inflammatory response that failed to resolve. Considering these differences as fundamental aspects of the genomic response to sepsis, interventional therapies will require individualization based on the age of the population ${ }^{2,17}$.

Ageing, in mice, affects every innate immune cell, including changes in cell numbers and function. Defects in the function of some cells are intrinsic, whereas for other cells, defects are extrinsic and possibly the consequence of the complex interactions with other cell types or the environmental milieu that is altered with aging. Abnormal function contributes to worsened outcomes after injury or infection and leads to diseases observed in the elderly ${ }^{18}$. The results from the present investigation give support to the hypothesis that the same kind of impaired immune response occurs in other elderly rodents, such as rats.

In human beings the factors influencing mortality from secondary bacterial peritonitis shows dominance of host related factors over the type and source of infection with high risk population identified by age over 60 years ${ }^{2,3,19}$. Even in mild very common surgical emergency such as appendicitis frequently seen in young adults, in whom the outcomes are usually good, in elderly this disease is becoming more prevalent and, it is far more serious requiring an early diagnosis and treatment, and even so associated with a mortality rate of about $3 \%$, and post-operative complication around $20 \%{ }^{20}$.

It has been understandable the knowledge that the immune system declines with age, a term known as immunosenescence, which leads to a higher incidence of infections, neoplasia and autoimmune diseases ${ }^{3}$.

The results from the present investigation make evident that the rats in group III (elderly) presented with a marked impaired immune response to the infectious challenge induced by the autogenously fecal peritonitis at the dosage of $6 \mathrm{ml} / \mathrm{kg}$. For keeping two (20\%) elderly rats alive it was necessary to break down the initial protocol and injecting three shots of intravenous meropenem $(40 \mathrm{mg} / \mathrm{kg})$ at post peritonitis induction, days 2 to 4. Although this outcome would be expected, it is necessary to assess the used model as regard to elderly rats. The usual dosage of autogenously $10 \%$ fecal suspension for testing therapeutically intervention is $5 \mathrm{ml} / \mathrm{kg}^{6,21}$. In these papers the rats included in the investigation weighed $300 \mathrm{~g}$ to $330 \mathrm{~g}$, however there was no mention to the ages of the rats in some studies ${ }^{5,6}$, and in other the rats were very young (between two and three months). In the present study it was followed a previous protocol ${ }^{16}$, in which it was produced a severe peritonitis and sepsis, but the rats were young (around 12 month-old). One limitation of this investigation was not foreseeing that the $6 \mathrm{ml} / \mathrm{kg}$ of $10 \%$ autogenously fecal suspension for producing severe peritonitis was an overwhelming infectious insult that the older rats could not overcome for the first $48 \mathrm{~h}$ post peritonitis induction, thus not allowing true comparison with the other two young rat groups that received intravenously meropenem after seven days post peritonitis induction.

One should speculate that in the elderly rats (18 monthold or more) the infectious insult could be done with a smaller dosage of $10 \%$ fecal suspension ( $4 \mathrm{ml}$ or $5 \mathrm{ml}$ per kilogram of rat), and the antimicrobial intervention should be earlier than seven days after peritonitis induction. Otherwise, the mortality of the elderly rats could be high at early time after peritonitis induction, as it happened in the present study, not allowing observations that would provide needed translational information for older septic human being.

Although the relationship between rat age and chronological age in human beings has been estimated in one rat day for 30 human days, there are other conversions that state this relation, in rat adult phase, could be 11.8 rat days $=1$ human year $^{22}$. In this study, using the conventional rate of conversion, the correspondence of rat age/human age, the translational information for human being age chronology would be: group I 18 year-old, group II 30 year-old, and group III 45 year-old. Notably, in the present investigation, the immune defense behavior of the older rats (group III) was of elderly people with impaired immune response (immunosenescence). Nevertheless, taking into account that the older rats were obese and sedentary, probably bearing comorbidities, the corresponding age for human beings should be in group III $\geq 45$ year-old ${ }^{22}$. This rate of age rat/human conversion could be more appropriate for explaining the early impaired immune response of the older rats in the present investigation.

In this regard, for researchers who are working with experimental infection, age in rats $^{22}$ is crucial for making analyses of the outcomes. The results from a therapeutically intervention can be absolutely different in some papers dealing with young animals when compared with other working with older rats. Thus, immune response to infection, in rats, can only be comparable if ages are stated in the investigation.

\section{Conclusions}

The treatment of severe autogenously fecal peritonitis with a single dosage of intravenous meropenem $(40 \mathrm{mg} / \mathrm{kg})$ reached reasonable results in rats with six and twelve months of age, even considering residual abscesses on abdomen and thorax cavities. However, the great majority of elderly rats could not overcome the 
initial severe infectious challenge, proving that ageing is a very important risk factor for impairing immune response. Thus, sepsis remains a challenging situation, especially in elderly, and working with experimental infection in rat model increasing age play a key role in the outcome interpretation.

\section{References}

1. Oaks WW, Cohen HE. Endotoxin shock in the geriatric patient Geriatrics. 1967;22:120-130. PMID: 5335496.

2. Aw D, Silva AB, Palmer DB. Immunosenescence of ageing. J G Pathol. 2007 Apr;120(4):435-46. PMID: 17313487.

3. Gruver AL, Hudson LL, Sempowski GD. Immunosenescence of ageing. J G Pathol. 2007 Jan;211(2):144-56. PMID: 17200946.

4. Wei CI, Gilliam MC, Cohen MD, Cornell JA, Moazam F. A preliminary study of age-related difference in resistence to sepsis in the rat model. J Surg Res. 1987 Nov;43(5):460-7. PMID: 3316844.

5. Kreimer F, Aguiar JLA, Castro CMMB, Lacerda CM, Reis T, Lisboa Júnior $\mathrm{F}$. Therapeutical and inflammatory response in rats with secondary peritonitis and topical use of ampicilin/sulbactam. Acta Cir Bras. 2005;20 Suppl 1:63-71. doi: org/10.1590/S010286502005000700007.

6. Brocco MC, Gomez RS, Paulo DN, Almeida CE, Baptista JF. Histological features of peritoneal lavage with ropivacaine in rats with fecal peritonitis. Acta Cir Bras. 2012 Feb;27(2):193-9. doi: org/10.1590/S0102-86502012000200016.

7. Perdue PW, Perdue PW, Kazarian KK, Nevola J, Law WR, Williams $\mathrm{T}$. The use of local and systemic antibiotics in rat fecal peritonitis. J Surg Res. 1994 Sep;57(3):360-5. PMID: 8072283.

8. Araujo ID, Grossi GCX, Diniz SOF, Nunes TA, Braga EÂ, Cardoso VN. Effects of the povidone-iodine (PVPI) in treatment of bacterial peritonitis induced in rats. Acta Cir Bras. 2010 Aug;25(4):322-7. doi: org/10.1590/S0004-28032005000200006.

9. Hyde SR, Stith RD, McCallum RE. Mortality and bacteriology of sepsis following cecal ligation and puncture in aged mice. Infect Immun. 1990 Mar;58(3):619-24. PMID: 2307515.

10. Pidhirnyı̌la, Baryliak R, Makovets'kyı̆ I, Shershen' H, Pidhirna M. Possibilities of combined and isolated application of carbapenems in patients with secondary widespread peritonitis. Klin Khir. 2009 Mar;(3):28-33. PMID: 19673118.

11. Guery BP. Doripenem: need for a new crabapenem. Med Mal Infect. 2009 Dec;39(12):891-6. doi: 10.1016/j.medmal.2009.08.014.

12. Yang Q, Wang H, Chen M, Ni Y, Yu Y, Hu B, Sun Z, Huang W, Hu Y, Ye H, Badal RE, Xu Y. Surveillance of antimicrobial susceptibility of aerobic and facultative Gram-negative bacilli isolated from patients with intra-abdominal infections in China: the 2002-2009 Study for Monitoring Antimicrobial Resistance Trends (SMART). Int J Antimicrob Agents. 2010 Dec;36(6):507-12. doi: 10.1016/j. ijantimicag.2010.09.001.

13. Badawy AA, Zaher TI, Sharaf SM, Emara MH, Shaheen NE, Aly TF. Effect of alternative antibiotics in treatment of cefotaxime resistant spontaneous bacterial peritonitis. World J Gastroenterol. 2013 Feb 18;19(8):1271-7. doi: 10.3748/wjg.v19.i8.1271.

14. Castagnola E, Bandettini R, Ginocchio F, Perotti M, Masa DL, Ciucci A, Loy A, Caviglia I, Haupt R, Guida E, Pini Prato A, Mattioli G, Buffa P. Susceptibility to antibiotics of aerobic bacteria isolated from community acquired secondary peritonitis in children: therapeutic guidelines might not always fit with and everyday experience. J Chemother. 2013 Aug;25(4):213-6. doi: 10.1179/1973947813Y.0000000083
15. Tuon FF, Rocha JL, Leite TM, Dias C. A simple mathematical model to determine the ideal empirical antibiotic therapy for bacteremic patients. Braz J Infect Dis. 2014 Jul-Aug;18(4):360-3. doi: 10.1016/j.bjid.2013.11.006.

16. Cavalcanti MMCS, Gadelha DB, Oliveira TKB, Brandt CT. Severe autogenously fecal peritonitis in Wistar rats with permanent bilateral carotid occlusion. Response to intra peritoneal moxifloxacin combined with dexamethasone. Acta Cir Bras. 2014 Feb;29(2):7681. doi: 10.1590/S0102-86502014000200001.

17. Gentile LF, Nacionales DC, Lopez MC, Vanzant E, Cuenca A, Cuenca AG, Ungaro R, Szpila BE, Larson S, Joseph A, Moore FA, Leeuwenburgh C, Baker HV, Moldawer LL, Efron PA. Protective immunity and defects in the neonatal and elderly immune response to sepsis. J Immunol. 2014 Apr 1;192(7):3156-65. doi: 10.4049/ jimmunol.1301726.

18. Kovacs EJ, Palmer JL, Fortin CF, Fülöp T Jr, Goldstein DR, Linton PJ. Aging and innate immunity in the mouse: impact of intrinsic and extrinsic factors. Trends Immunol. 2009 Jul;30(7):319-24. doi: 10.1016/j.it.2009.03.012.

19. Omari AH, Muhammad R Khammash MR, Qasaime GR, Ahmad K Shammari AK, Yaseeb MKB, Hammori SK. Acute appendicitis in the elderly: risk factors for perforation. World J Emerg Surg. 2014 Jan 15;9(1):6. doi: 10.1186/1749-7922-9-6.

20. Ramakrishnaiah VP, Chandrakasan C, Dharanipragadha K, Sistla S, Krishnamachari S. Community acquired bacterial peritonitis in a tertiary hospital of South India: an audit with special reference to peritoneal fluid culture. Trop Gastroenterol. 2012 OctDec;33(4):275-81. PMID: 23923354.

21. Carneiro BGM, Petroianu A, Rodrigues FHOC, Rocha RF. Estudo comparativo entre diversos tipos de tratamento para peritonite fecal em rato. Rev Col Bras Cir. 2002;29(1):43-48. doi: org/10.1590/ S0100-69912002000100009.

22. Sengupta P. The Laboratory Rat: Relating Its Age With Human's. Int J Prev Med. Jun 2013;4(6):624-30. PMID: 23930179.

\section{Correspondence:}

Carlos Teixeira Brandt

Avenida Boa Viagem, 5030/1302

51011-000 Recife - PE Brasil

Tel.: (55 81)3342-0830

carlosbrandt@bol.com.br

Received: Apr 18, 2014

Review: Jun 18, 2014

Accepted: July 22, 2014

Conflict of interest: none

Financial source: Medical Sciences, Faculty of Campina Grande

${ }^{1}$ Research performed at Experimental Research Unit, Campina Grande Faculty of Medicine (FCM), Campina Grande-PB, Brazil. Part of Master degree thesis, Postgraduate Program in Surgery, Federal University of Pernambuco (UFPE). Tutor: Prof. Carlos Teixeira Brandt. 